encontrar formas de reduzir os mecanismos causadores adversos e propiciar, à sociedade, desenvolvimento dentro dessas limitaçóes.

Mas os cientistas também terão de reconhecer que, enquanto ciência e tecnologia são importantes, a transformação social o é ainda mais. Existem muitas formas através das quais, mesmo hoje, podemos mitigar aspectos das alteraçóes globais, e contribuir para uma diminuição significativa da pobreza. Mas isso náo está acontecendo. O problema está na esfera crucial das relaçóes humanas. Os cientistas devem se aperceber de que, além de desenvolver a ciência e suas aplicaçóes no sentido do desenvolvimento sustentável, a ciência deve forjar laços com outros setores da sociedade: com ciências sociais e engenharia, com negócios e indústria, com organizaçóes governamentais e intergovernamentais e, mais importante, com os setores náo-governamentais independentes que voluntariamente trabalham diretamente com a sociedade. A comunidade científica deve reconhecer que é parte da sociedade e deve contribuir para as transformações sociais, elas sim essenciais para o desenvolvimento sustentável.

A consciência científica internacional está alerta e trabalhando para unir recursos, tanto físicos como morais, necessários para que se tenha um desenvolvimento sustentável.

\title{
Ciência e Tecnologia: O Problema da Criação de Capacidade no Terceiro Mundo
}

\author{
ROBERTO LEAL LOBO E SIVVA FILHO \\ (Instituto de Física e Quimica da USP de São Carlos, Brasil)
}

hiato tecnológico entre os países desenvolvidos e os chamados em
desenvolvimento, longe de diminuir, como se esperava alguns anos
atrás, parece estar constantemente aumentando. A continuar essa ten-
dência, os países em desenvolvimento permaneceráo como uma promes- 
sa não realizada por muitas décadas ou mesmo séculos. Talvez, em poucos anos, seja mais realista voltar a usar velhos termos - países desenvolvidos e subdesenvolvidos - e o sonho de uma melhor distribuição planetária de riqueza pode transformar-se em autêntico pesadelo para a humanidade.

Um mundo dividido, com um contingente de pessoas ricas cercadas de uma multidáo de seres miseráveis não é, certamente, o tipo de sociedade aceitável por qualquer um de nós como futuro para a vida humana neste planeta. Esta sociedade seria precária e instável e, talvez, como conseqüência uma nova idade das trevas cairia sobre nossas cabeças, desenvolvidas ou náo.

Atualmente, $o$ acesso à tecnologia parece ser a chave que abre as portas para o crescimento econômico. Apenas através da criação e absorção de novas tecnologias parece ser possível, para os países menos desenvolvidos, evitar a trilha divergente que os conduz por caminhos cada vez mais distantes daqueles trilhados pelo Primeiro Mundo.

Para criar uma base tecnológica sólida, pelo menos dois requisitos nos parecem fundamentais: a existência de um sistema educacional forte e uma provisáo de recursos financeiros para a manutenção e estímulo das pesquisas em C\&T. É evidente que, em países carentes de recursos, investimentos em pesquisa têm de competir com outras prioridades que parecem ser ainda mais dramáticas: educaçáo básica, saúde, transportes, habitação etc. A despeito da competição entre essas prioridades, é preciso entender-se ser a prioridade da pesquisa também dramática, e talvez mais dramática a longo prazo que as demais. É fundamental, por isso, a compreensão de que a tecnologia é uma das condiçóes necessárias para o desenvolvimento e que é da responsabilidade dos governantes encontrar formas de estimular o fluxo de fundos públicos e privados para as atividades de pesquisa, incentivando a ação conjunta dos dois segmentos de acordo com um planejamento estratégico nacional.

Acho importante, neste ponto, mencionar outra dificuldade que países como o Brasil estão encontrando não apenas em criar, mas mesmo em absorver tecnologias correntes. Em alguns casos extremos, chega-se a proibir a países irresponsáveis a utilização de materiais considerados intocápeis pelos detentores da tecnologia. É notório algumas tecnologias sofisticadas serem protegidas pelos países mais desenvolvidos, que usam como argumento a náo-confiabilidade de governos de países do Terceiro Mundo. Não pretendo me aprofundar nesse tema, que considero um parêntese neste texto. Como reitor de uma universidade brasileira, no entanto, confrontei-me com tal realidade. Acho mesmo que 
as razões usadas para justificar essa política possam ter sido razoáveis em poucos casos específicos, mas elas correm o perigo de se tornarem mera proteção comercial da tecnologia, levando a um oligopólio do conhecimento que viola claramente os princípios do mercado livre - princípio que nos é apresentado pelos países desenvolvidos como a principal exigência da modernidade!

Além das dificuldades advindas de um excesso de prioridades, da carência de capital e de acesso ao denominado de tecnologias sensíveis, o Terceiro Mundo sofre também de doenças geradas internamente. Aqui, devo falar de minha própria experiência no Brasil, um país grande que gasta em educaçáo uma quantia per capita comparável (embora menor), à dispendida por países mais desenvolvidos, mas investe em ciência e tecnologia um valor per capita de apenas um oitavo do dispendido por esses mesmos países. Dessa pequena alocaçáo, cerca de $\mathbf{8 0 \%}$ vêm de fontes governamentais (sejam federais ou estaduais). Como regra, as grandes indústrias brasileiras, independentemente de terem ou não capital nacional, compram tecnologia externa. Isso é compreensível, em parte, devido a que, com o alto nível da inflaçáo brasileira, investimentos de longo prazo não são compensadores. É mais fácil, mais prático e mais rentável investir no mercado financeiro com altas taxas de juros e liquidez garantida pelo governo. Além disso, a comunidade científica brasileira não apresenta um currículo suficientemente forte em termos de conquistas tecnológicas e, assim, existe pouca confiança no que diz respeito ao retorno dos investimentos em P\&D. Mas, mesmo considerando todos os argumentos altamente razoáveis dados acima, os investimentos em pesquisa feitos pelas grandes indústrias no Brasil são desapontadoramente baixos. Precisamos, de alguma forma, interromper esse ciclo vicioso: falta de investimento inibindo a produção de C\&T e falta de produçáo inibindo os investimentos.

Por outro lado, as universidade e os centros de pesquisa, os geradores de conhecimento em ciência e tecnologia, ainda se debatem em torno de questóes ideológicas relacionadas, muitas vezes, mais com interesses político-partidários do que propriamente com a qualidade acadêmica ou com as novas missóes das universidades na época atual. Muitas vezes, a discussão é levada a seu limite assintótico, gerando um maniqueísmo perverso: a universidade deve fazer pesquisa básica ou aplicada? Deve ser um elemento crítico de transformaçáo social ou trabalhar junto às empresas nacionais? Estou certo de serem estes conflitos mais retóricos do que reais. O futuro vai nos impor - como o presente já impóe - que as universidades náo somente aprimorem seu gerenciamento mas abram definitivamente suas portas à sociedade, através de programas 
que coloquem lado a lado, como parceiros reais, as universidades e os mais diferentes segmentos da sociedade, de forma coordenada e sem preconceitos.

Para vencer a enorme distância que os separa do Primeiro Mundo, algumas estratégias devem ser implementadas nos países do Terceiro Mundo, como é o caso do Brasil, para ajudar a acelerar o esforço tecnológico para o desenvolvimento. Na Universidade de São Paulo, por exemplo, um programa chamado Disque-tecnologia foi iniciado há dois anos com o objetivo de colaborar com pequenos e médios empresários em todas as áreas nas quais a Universidade tivesse alguma capacitaçáo. Hoje, são cerca de $\mathbf{4 0 0 0}$ os professores cadastrados no programa na qualidade de consultores e mais de $\mathbf{3 0 0 0}$ empresas já se beneficiaram dele. Além disso, muitas empresas-júnior criadas por estudantes de graduaçáo também vêm dando apoio ao programa quando o problema cai dentro de sua área de competência. Disque tecnologia foi estendido a outros estados brasileiros com o apoio do SEBRAE e está sendo implementado, a partir do modelo USP, na Costa Rica e no Uruguai. $O$ exemplo mostra um dos possíveis modos de açáo para universidades de países em desenvolvimento, que pode ser muito eficiente para criar uma base tecnológica nacional, gerar empregos e desenvolver a confiança mútua entre as universidades $\mathrm{e}$ a indústria. Outras relevantes iniciativas em distintos países não são difíceis de ser identificadas. O levantamento de iniciativas bem-sucedidas poderia ser o ponto inicial para um projeto nacional de desenvolvimento.

Acredito também que a escassez de recursos impóe um planejamento de médio prazo na formaçáo de recursos humanos na área de C\&T. Os programas de bolsas e auxílios devem levar em conta náo somente a qualidade acadêmica dos candidatos, mas também as necessidades do País com relação à formação de especialistas em áreas básicas para o desenvolvimento. É claro que não se deve inibir a formação de pessoas talentosas em outras áreas de conhecimento, mas países pobres não podem se dar ao luxo de estimular muitas delas em áreas por demais distantes da realidade nacional. A pesquisa fundamental dispendiosa deve se restringir a áreas nas quais o país tenha tradição e massa crítica mínimas. Outras, podem ser levadas adiante através de cooperaçáo com centros mais desenvolvidos em países ou centros internacionais com maiores condiçóes de investimento e de seu retorno mais imediato.

Por fim, penso que seria conveniente criar um fundo de investimentos em pesquisas tecnológicas, oriundo dos processos de aquisição de tecnologia do exterior, através da cobrança de uma sobretaxa específica. Esta deveria ser cuidadosamente estabelecida para evitar o desestí- 
mulo aos projetos de aquisiçáo de tecnologia internacional, e aplicada para financiar pesquisas nos países em desenvolvimento que se mostrassem dispostos a aumentar a competitividade de suas empresas com o apoio das universidades e centros de pesquisa. Essa proposta náo é nova. Para reforçar tal programa, seria muito bem-vinda a criaçáo de um fundo internacional devotado a suplementar os fundos locais. Uma agência - ou banco internacional - poderia ser usada com esse propósito, o que certamente contribuiria para diminuir o hiato tecnológico entre os dois mundos e evitar o pesadelo que nos ameaça.

\title{
INVESTIMENTOS EM CIÊNCIA E TeCnologia
}

\author{
ARON KUPPERMANN \\ (California Institute of Technology, Pasadena, EUA)
}

\begin{abstract}
apoio à ciência e à tecnologia em um mundo em rápida mudança está sendo fortemente escrutinizado, tanto nos países desenvolvidos como nos em desenvolvimento. Entre as questóes levantadas estão: Por que apoiar C\&T? Qual fração dos recursos da sociedade deve ser alocada para essa atividade? Como repartir esses recursos entre pesquisa básica, pesquisa aplicada e desenvolvimento tecnológico? Quais devem ser os mecanismos de apoio? Podem tais investimentos ser feitos de forma ecologicamente segura e compatível com uma sociedade sustentável? Essas são questóes duras e importantes que se procurará discutir no presente artigo. Algumas das respostas são aquelas válidas há $\mathbf{5 0}$ anos $\mathrm{e}$ têm um forte elemento de permanência. Outras estão em processo de mudança fundamental e sujeitas ao debate e análise internacionais. Este encontro é uma das várias manifestaçōes desse escrutínio realizado pela comunidade internacional de cientistas interessados, tecnólogos, educadores, economistas, sociólogos e políticos. O resultado de discussões dessa natureza deve ajudar a dar forma ao futuro deste planeta e de seus habitantes.
\end{abstract}

Por que a ciência deve ser apoiada pela sociedade? Existem muitas 